\title{
Feasibility and Safety of Transradial Stenting for Unprotected Left Main Coronary Artery Stenoses
}

\author{
Cheng-I Cheng, MD*,**; Chiung-Jen Wu, MD**; Chih-Yuan Fang, MD**; \\ Ali A. Youssef, MD**; Chien-Jen Chen, MD**; Shyh-Ming Chen, MD**; \\ Cheng-Hsu Yang, MD**; Shu-Kai Hsueh, MD**; Hon-Kan Yip, MD**; \\ Mien-Cheng Chen, MD**; Morgan Fu, MD**; Yuan-Kai Hsieh, MD**
}

\begin{abstract}
Background Percutaneous coronary intervention (PCI) is considered an excellent alternative treatment for unprotected left main coronary artery (ULMCA) stenoses. Most PCIs for ULMCA stenoses are performed via the transfemoral approach. The feasibility and safety of the transradial approach for this particular entity are unknown. The present study assessed the feasibility, safety and 1-year outcomes of the transradial approach for stenting of ULMCA stenoses.

Methods and Results Of 131 consecutive patients who underwent coronary stenting for ULMCA stenoses, 113 patients $(86.3 \%)$ received stenting using the transradial approach. All 113 procedures were performed with 6 or 7 French $(\mathrm{Fr})$ catheters except 1 procedure requiring an 8 Fr guiding catheter for directional atherectomy. The technical success rate was $100 \%$, and angiographic success was achieved in 96 patients (85.9\%). Two patients had local hematoma (1.8\%), and no procedure-related deaths, Q-wave myocardial infarction, repetitive PCI, stroke or emergent coronary artery bypass graft surgery during hospitalization were noted. One (0.9\%) in-hospital cardiac death occurred due to ventricular tachyarrhythmia. More than half of our patients stayed in hospital by $\leq 3$ days. The 1-year target lesion revascularization and cardiac death rate were $14.2 \%$ and $3.5 \%$, respectively.

Conclusions This investigation demonstrated the feasibility, safety and accepted short-term clinical outcomes of transradial stenting for ULMCA stenosis. This procedure may offer a feasible alternative to the transfemoral approach. (Circ J 2007; 71: 855-861)
\end{abstract}

Key Words: Coronary stenting; Left main coronary disease; Transradial approach

A

opposed to 1- or 2-vessel coronary artery diseases (CAD), patients with unprotected left main artery disease carry poor outcomes if left unrevascularized!, 2 Percutaneous coronary intervention (PCI) is regarded as a potential alternative management of unprotected left main coronary artery (ULMCA) disease to coronary artery bypass graft surgery $(\mathrm{CABG})$ in selected patients due to comparable short-term clinical results ${ }^{3-5}$ Given the high percentage of distal bifurcation lesions and the large vessel diameter in ULMCA disease, most PCI for ULMCA stenoses are performed via the transfemoral approach using either 7 or 8 French $(\mathrm{Fr})$ guiding catheters ${ }^{6-9}$ With recent advances in PCI instruments and techniques, most coronary lesions can now be safely treated via the transradial approach with a high procedural success rate and relatively few local vascular complications! ${ }^{10,11}$ Nevertheless, the literature review reveals few case reports regarding transra-

(Received November 28, 2006; revised manuscript received February 13, 2007; accepted March 7, 2007)

*Graduate Institute of Clinical Medical Sciences, Chang Gung University College of Medicine, Kaohsiung, **Division of Cardiology, Department of Internal Medicine, Chang Gung Memorial HospitalKaohsiung Medical Center, Taiwan, Republic of China

This study received no funding and no author has any commercial associations or interests, including consultancies, stock ownership or other competing equity interests or patent-licensing arrangements.

Mailing address: Yuan-Kai Hsieh, MD, Division of Cardiology, Department of Internal Medicine, Chang Gung Memorial HospitalKaohsiung Medical Center, No.123, Ta-Pei Road, Niao-Sung Township, Kaohsiung County, 83301, Taiwan, Republic of China. E-mail: kelvintw@so-net.net.tw dial stenting for ULMCA disease and only one small-scale study comparing the transradial and the transfemoral approach for both protected and unprotected left main PCI ${ }^{2-15}$ Thus, the feasibility and safety of routine transradial stenting for ULMCA stenoses remains unclear. To elucidate the feasibility and safety of this procedure, we retrospectively reviewed the success rate, in-hospital complications and 1year outcomes of patients undergoing transradial coronary stenting for ULMCA stenoses in our medical facility.

\section{Methods}

\section{Study Population and Procedures}

All patients undergoing elective coronary stent implantation in Chang Gung Memorial Hospital-Kaohsiung Medical Center, between June 2001 and August 2006, for ULMCA diseases with diameter stenosis $\geq 50 \%$ were selected for retrospective analysis. Patients presenting with ST-segment elevation acute myocardial infarction (MI) were excluded from the present study. Instead of surgery, PCI was chosen when suitable anatomy for stenting via a percutaneous approach was present and CABG was considered high risk owing to the presence of either old age or comorbidity, or in cases involving simple patient preference, which was defined as $\mathrm{CABG}$ eligibility. The unilateral radial artery was punctured routinely for the initial coronary angiogram at our institute unless patients had positive Allen's test, weak radial artery pulsation, wrist joint deformity or a local wound unsuitable for this approach. If the puncture of bilateral radial arteries failed, either the 
Utilization rate

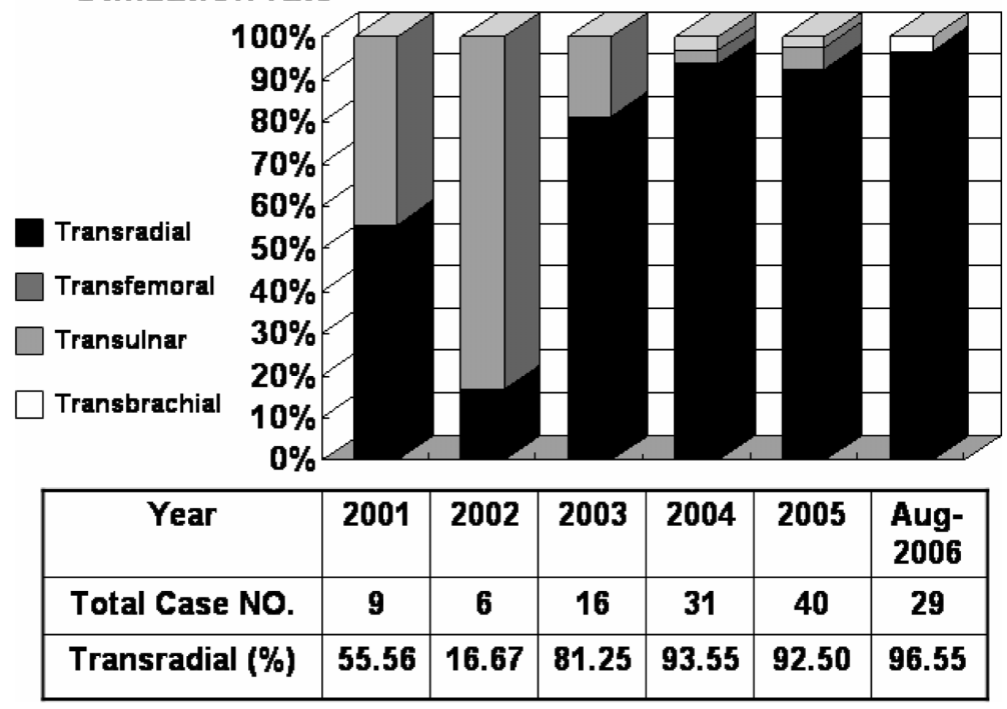

Fig 1. Utilization rate of different approach sites for percutaneous coronary interventions for unprotected left main coronary artery stenoses. Utilization rate of different approach sites for percutaneous coronary interventions for unprotected left main coronary artery stenosis are presented year by year as a bar chart. Total case number and transradial penetration rate each year are also presented in Table. femoral, brachial or ulnar arteries would be utilized. Once the diagnosis of ULMCA stenosis was established, operators were free to choose the transradial approach for PCI or shift to other approach sites if a larger guiding catheter size was considered necessary for the intervention. All patients were routinely administered a mixture of 5,000 units of unfractionated heparin, $200 \mu \mathrm{g}$ of nitroglycerin and $2.5 \mathrm{mg}$ of verapamil into the artery sheath once the radial artery was cannulated with a 6 Fr sheath. Based on the angiographic findings and selected PCI technique, a 6 Fr radial artery sheath was exchanged for a $7 \mathrm{Fr}$ or then stepwise to a $8 \mathrm{Fr}$ sheath if necessary. Before PCI, an additional 5,000 units of unfractional heparin was administered through the guiding catheter following the diagnostic coronary angiogram. Techniques for stent deployment were as described by Iakovou et al ${ }^{16}$ High-pressure balloon dilatation was defined as maximal inflation pressure $\geq 16$ atmosphere (atm). Coronary angiograms were analyzed using a semi-automated quantitative computer analysis system-Cardiovascular Medical System ${ }^{\mathrm{TM}}$ (Philip Medical System, Best, the Netherlands) at the baseline and following the procedure.

\section{Definitions and Study Endpoints}

The events selected for analysis in this investigation of clinical outcomes included technical success, angiographic success, procedural success, local vascular complications, in-hospital cardiovascular events and duration of hospitalization. Technical success was defined as successful cannulation using an artery sheath with one unilateral radial artery, advancement and engagement of guiding catheter and performance of intended PCI technique without crossover to another vascular access site. Angiographic success was defined as a residual diameter stenosis $<30 \%$ and grade 3 Thrombolysis In Myocardial Infarction (TIMI) flow on angiography at the target lesion. Procedural success was defined as angiographic success without procedure-related death, Q wave MI, repetitive PCI, stroke or emergent CABG during hospitalization. Local vascular complications included regional ischemic change, radial artery occlusion, local hematoma $>5 \mathrm{~cm}$ in diameter, arteriovenous fistula, pseudoaneurysm and bleeding complications compatible with TIMI major or minor criteria for bleeding complications $!^{17}$ In-hospital cardiovascular events included post- procedural MI (Q wave or non-Q wave), repetitive PCI, CABG, acute (within $24 \mathrm{~h}$ ) or subacute (within 1 month) thrombosis, ventricular tachyarrhythmia, pulmonary edema, stroke and death occurring during hospitalization. Non-Q wave MI was defined as an elevation of total creatine kinase (CK) greater than twice the normal upper limit with a positive MB fraction in the absence of pathological Q waves on ECG? Deaths were classified as either cardiac or non-cardiac. Major adverse cardiac events (MACE) were defined as cardiac death, stroke, non-fatal MI and target lesion revascularization (TLR), occurring either in hospital or during the 1-year follow-up. Deaths from unknown causes were considered cardiac-related. Renal insufficiency was defined as serum creatinine $>1.4 \mathrm{mg} / \mathrm{dl}$, and hyperlipidemia was defined as serum total cholesterol $>200 \mathrm{mg} / \mathrm{dl}$. The European system of cardiac operative risk assessment (EuroSCORE) was used to stratify the mortality risk at 30 days and patients with a EuroSCORE 0 to 2 were classified as low risk, 3 to 5 as moderate risk and $\geq 6$ as high risk ${ }^{18}$

\section{Statistical Analysis}

Data were expressed as mean \pm SD for continuous variables and as frequencies for categorical variables. Differences between groups were assessed using chi-square statistics for categorical variables and independent sample t-test for continuous variables. Distributions of cardiac deaths, all-cause mortality, TLR and MACE-free survival were estimated using the Kaplan-Meier method. All statistical analyses were performed using SPSS 13.0 for Windows (SPSS Inc, Chicago, IL, USA).

\section{Results}

\section{Penetration Rate of Transradial Approach}

During the same study period, 324 patients were diagnosed to have ULMCA stenoses based on the coronary angiogram performed at our catheterization lab, and 193 patients $(59.6 \%)$ were sent for CABG. Of 131 patients undergoing PCI for ULMCA stenoses, 113 patients $(86.3 \%)$ receiving transradial stenting were enrolled for analysis. Fig 1 shows the utilization rate of the transradial approach by year. PCI for ULMCA stenosis in our institute began in December 2000, and the transfemoral approach was initial- 
Table 1 Baseline Clinical Characteristics

\begin{tabular}{|c|c|}
\hline & Patients $(n=113)$ \\
\hline Age (years) & $67.6 \pm 10.3$ \\
\hline Body weight $(\mathrm{kg})$ & $65.1 \pm 11.3$ \\
\hline Body height $(\mathrm{cm})$ & $160.8 \pm 8.2$ \\
\hline Body mass index & $25.05 \pm 3.56$ \\
\hline Male (\%) & $87(77.0 \%)$ \\
\hline Hypertension (\%) & $77(68.1 \%)$ \\
\hline Diabetes mellitus (\%) & $42(37.2 \%)$ \\
\hline Current smoking (\%) & $41(36.3 \%)$ \\
\hline Hyperlipidemia (\%) & $82(72.6 \%)$ \\
\hline Renal insufficiency (\%) & $26(23.3 \%)$ \\
\hline Prior MI (\%) & $26(23.0 \%)$ \\
\hline Prior stroke (\%) & $13(11.5 \%)$ \\
\hline$P V D(\%)$ & $14(12.5 \%)$ \\
\hline Prior PTCA (\%) & $49(43.4 \%)$ \\
\hline Mean LVEF (\%) & $56.8 \pm 13.4$ \\
\hline$L V E F<40 \%(\%)$ & $13(11.5 \%)$ \\
\hline CHF NYHA Fc III \&IV (\%) & $12(10.4 \%)$ \\
\hline EuroSCORE-mean & $7.4 \pm 3.7$ \\
\hline Low risk (1-2) (\%) & $2(1.8 \%)$ \\
\hline Moderate risk (3-5) (\%) & $39(34.5 \%)$ \\
\hline High risk $(\geq 6)(\%)$ & $72(63.7 \%)$ \\
\hline \multicolumn{2}{|c|}{ Clinical presentation as revasculization indication } \\
\hline Stable angina $(\%)$ & $18(15.9 \%)$ \\
\hline Unstable angina $(\%)$ & $74(65.5 \%)$ \\
\hline $\operatorname{NSTEMI}(\%)$ & $14(12.4 \%)$ \\
\hline $\mathrm{CHF}(\%)$ & $7(6.2 \%)$ \\
\hline$C A B G$ eligibility (\%) & $88(77.9 \%)$ \\
\hline
\end{tabular}

MI, myocardial infarction; $P V D$, peripheral vascular disease; PTCA, percutaneous transluminal coronary angioplasty; LVEF, left ventricular ejection fraction; $\mathrm{CHF}$, congestive heart failure; NYHA Fc, New York Heart Association functional class; NSTEMI, non-ST segment elevation myocardial infarction; $C A B G$, coronary artery bypass surgery.

ly the routine method for managing this complex coronary lesion. With the exception of 2002, when debulking by either directional atherectomy or rotational atherectomy was performed in 5 cases via the transfemoral approach, the penetration rate of transradial stenting increased year by year. Because the diagnostic coronary angiogram was routinely performed via the transradial approach in our hospital, the transradial approach has become the routine PCI route for ULMCA stenoses since year 2004, and the failure rate of radial artery access was 6.0\% (6 of 100 patients). Puncture of the femoral artery was required in 3 patients, brachial artery in 2 patients and ulnar artery in 1 patient. After the radial artery was cannulated using a 6 or 7 Fr artery sheath, a coronary angiogram and subsequent PCI for ULMCA stenoses was performed successfully with the proper selection of guiding catheters. No cases required a change to transfemoral approach due to technique failure. The technique success rate was $94 \%$ by definition.

\section{Patient Characteristics}

Table 1 lists the baseline characteristics of 113 patients undergoing transradial stenting for UMLCA stenoses. The mean age of these patients was $67.6 \pm 0.3$ year and 87 patients $(77.0 \%)$ were male. Seventy-seven patients $(68.1 \%)$ had a history of hypertension, 42 patients $(37.2 \%)$ were diabetic, 41 patients $(36.3 \%)$ were current smokers, 82 patients (72.6\%) were hyperlipidemic and 26 patients $(23.0 \%)$ had renal insufficiency. Prior MI and prior stroke were documented in 26 patients $(23.0 \%)$ and 13 patients $(11.5 \%)$, respectively, while 49 patients $(43.4 \%)$ had previous PCI for coronary lesions other than ULMCA stenoses. Thirteen patients $(11.5 \%)$ had a left ventricular (LV) ejection frac-
Table 2 Angiographic Characteristics

\begin{tabular}{|c|c|}
\hline & Patients $(n=113)$ \\
\hline \multicolumn{2}{|l|}{ Diseased vessel } \\
\hline LMCA only (\%) & $4(3.5 \%)$ \\
\hline$L M C A \& 1$ vessel $(\%)$ & $12(10.6 \%)$ \\
\hline LMCA \& 2 vessels (\%) & $28(24.8 \%)$ \\
\hline$L M C A \& 3$ vessels (\%) & $66(58.4 \%)$ \\
\hline LMCA, ramus \& 3 vessels (\%) & $3(2.7 \%)$ \\
\hline Occluded LAD (\%) & $10(8.0 \%)$ \\
\hline Occluded LCX (\%) & $8(7.1 \%)$ \\
\hline Occluded RCA (\%) & $15(13.3 \%)$ \\
\hline Bifurcation lesion (\%) & $84(74.3 \%)$ \\
\hline De novo lesion (\%) & $110(97.3 \%)$ \\
\hline \multicolumn{2}{|l|}{ AHA lesion classification } \\
\hline B1 (\%) & $10(8.8 \%)$ \\
\hline$B 2(\%)$ & $70(61.9 \%)$ \\
\hline$C(\%)$ & $33(29.2 \%)$ \\
\hline \multicolumn{2}{|l|}{ TIMI flow } \\
\hline II (\%) & $8(7.1 \%)$ \\
\hline III $(\%)$ & $105(92.9 \%)$ \\
\hline Pre-MLD (mm) & $1.19 \pm 0.64$ \\
\hline Pre-RVD $(\mathrm{mm})$ & $3.62 \pm 0.64$ \\
\hline Diameter stenosis (\%) & $66.9 \pm 15.2$ \\
\hline Lesion length (mm) & $16.23 \pm 10.00$ \\
\hline Post-MLD (mm) & $3.70 \pm 0.59$ \\
\hline Post-RVD (mm) & $4.10 \pm 0.55$ \\
\hline Residual stenosis (\%) & $10.0 \pm 9.9$ \\
\hline Acute gain $(\mathrm{mm})$ & $2.51 \pm 0.83$ \\
\hline Stent/reference ratio & $0.97 \pm 0.13$ \\
\hline \multicolumn{2}{|l|}{ Dissection on final angiogram } \\
\hline No dissection (\%) & $107(94.7 \%)$ \\
\hline Type A (\%) & $5(4.4 \%)$ \\
\hline Type B (\%) & $1(0.9 \%)$ \\
\hline Angiographic success (\%) & $111(98.2 \%)$ \\
\hline Complete revasculization (\%) & $55(48.7 \%)$ \\
\hline
\end{tabular}

LMCA, left main coronary artery; LAD, left anterior descending artery; $L C X$, left circumflex artery; RCA, right coronary artery; AHA, American Heart Association; TIMI, Thrombolysis In Myocardial Infarction; MLD, minimal lumen diameter; RVD, reference vessel diameter.

tion of less than $40 \%$ documented either by echocardiography or left vetriculogram during cardiac catheterization, and the mean LV ejection fraction of the study subjects was $56.8 \pm 13.4 \%$. Twelve patients $(10.6 \%)$ had clinically diagnosed heart failure compatible with New York Heart Association Function Class III or IV. The mean EuroSCORE was $7.4 \pm 3.7$, and 72 patients $(63.7 \%)$ were defined as high risk with EuroSCORE $\geq 6$. Among those undergoing transradial stenting for ULMCA stenoses, 88 patients $(77.9 \%)$ refused $\mathrm{CABG}$ as a choice of treatment, whereas the remaining 25 patients $(22.1 \%)$ were considered unsuitable for CABG owing to either limited life span, severe comorbid disease or high surgical risk.

\section{Angiographic Characteristics}

Table 2 summarizes the angiographic findings. Sixtynine patients $(61.1 \%)$ had ULMCA and multi-vessel CAD. Cases of totally occluded left anterior descending artery (LAD), left circumflex artery (LCX) and right coronary artery were $8.0 \%, 7.1 \%$ and $13.3 \%$, respectively. The lesions were located at distal the ULMCA bifurcation area in 84 patients $(74.3 \%)$ and were classified according to the American Heart Association lesion classification system as either B2 or C in 103 patients (91.2\%). TIMI III flow was noted in 105 patients $(92.9 \%)$ on initial coronary angiogram. De novo lesions were identified in 110 patients (97.3\%), while 3 patients of the present study group $(2.7 \%)$ 
Table 3 Procedural Characteristics

\begin{tabular}{|c|c|}
\hline & Patients $(n=113)$ \\
\hline Procedure time (min) & $84.0 \pm 33.9$ \\
\hline Ad hoc PCI (\%) & $59(52.2 \%)$ \\
\hline Left radial/femoral approach (\%) & $81(71.7 \%)$ \\
\hline \multicolumn{2}{|l|}{ Catheter size } \\
\hline $6 \operatorname{Fr}(\%)$ & $96(85.0 \%)$ \\
\hline $7 \operatorname{Fr}(\%)$ & $16(14.2 \%)$ \\
\hline $8 \operatorname{Fr}(\%)$ & $1(0.9 \%)$ \\
\hline \multicolumn{2}{|l|}{ Catheter type } \\
\hline Kimny radial or Kimny-mini radial (\%) & $70(61.9 \%)$ \\
\hline Jukin left $3.5,4.0$ or $4.5(\%)$ & $25(22.1 \%)$ \\
\hline$X B 4.0$ or $4.5(\%)$ & $7(6.3 \%)$ \\
\hline Amplatz left 1 or $2(\%)$ & $4(3.5 \%)$ \\
\hline$E B U(\%)$ & $2(1.8 \%)$ \\
\hline Ikari left $3.5(\%)$ & $5(4.4 \%)$ \\
\hline Temporal pacemaker (\%) & $0(0 \%)$ \\
\hline IABP support (\%) & $5(4.4 \%)$ \\
\hline IVUS guide (\%) & $58(51.3 \%)$ \\
\hline \multicolumn{2}{|l|}{ Lesion modification } \\
\hline$D C A(\%)$ & $1(0.9 \%)$ \\
\hline Rotablation (\%) & $1(0.9 \%)$ \\
\hline$C B A(\%)$ & $6(5.3 \%)$ \\
\hline Direct stenting (\%) & $18(15.9 \%)$ \\
\hline Stent covering at LMCA ostium (\%) & $49(43.4 \%)$ \\
\hline Stent crossing bifurcation (\%) & $89(78.8 \%)$ \\
\hline DES penetration (\%) & $77(67.3 \%)$ \\
\hline Number of stents-mean & $1.3 \pm 0.5$ \\
\hline $1(\%)$ & $80(70.8 \%)$ \\
\hline $2(\%)$ & $33(29.2 \%)$ \\
\hline \multicolumn{2}{|l|}{ Stent deployment technique } \\
\hline 1 stent without kissing balloon (\%) & $40(35.4 \%)$ \\
\hline 1 stent with kissing balloon (\%) & $40(35.4 \%)$ \\
\hline Simultaneous kissing stent (\%) & $1(0.9 \%)$ \\
\hline Modified crush (\%) & $9(8.0 \%)$ \\
\hline Crush (\%) & $1(0.9 \%)$ \\
\hline Cullote (\%) & $19(16.8 \%)$ \\
\hline T stent $(\%)$ & $2(1.8 \%)$ \\
\hline Provisional T stent (\%) & $1(0.9 \%)$ \\
\hline Stent length $(\mathrm{mm})$ & $26.15 \pm 6.58$ \\
\hline Stent width $(\mathrm{mm})$ & $3.43 \pm 0.32$ \\
\hline Maximal pressure (atm) & $18.7 \pm 5.6$ \\
\hline Additional NC balloon dilatation (\%) & $42(37.2 \%)$ \\
\hline High pressure inflation $\geq 16$ atm (\%) & $87(77.0 \%)$ \\
\hline Final kissing balloon (\%) & $71(62.8 \%)$ \\
\hline Procedural success (\%) & $111(98.2 \%)$ \\
\hline
\end{tabular}

$P C I$, percutaneous coronary intervention; $F r$, French; IABP, intra-aortic balloon pumping; IVUS, intravascular ultrasound; DCA, directional coronary atherectomy; CBA, cutting balloon angioplasty; DES, drug-eluting stent; NC, non-compliant. Other abbreviation see in Table 2.

had restenotic lesions after directional atherectomy. The mean minimal lumen diameter and mean reference vessel diameter were $1.19 \pm 0.64 \mathrm{~mm}$ and $3.61 \pm 0.64 \mathrm{~mm}$, respectively, and mean lesion length was $16.23 \pm 10.00 \mathrm{~mm}$ before PCI. The stent-to-reference ratio was $0.97 \pm 0.13$, and acute gain was $2.51 \pm 0.83 \mathrm{~mm}$ at the final angiogram, with a mean residual stenosis of $10.4 \pm 9.9 \%$. Type $\mathrm{A}$ and $\mathrm{B}$ dissection were noted at the distal stent edge in 5 patients $(4.4 \%)$ and 1 patient $(0.9 \%)$, respectively, on final angiogram without flow limitation. Angiographic success was achieved in 111 patients $(98.2 \%)$, and complete revascularization was observed in 55 patients $(48.7 \%)$ after coronary interventions. In 2 patients, whose angiography was unsuccessful, one was because of chronic total occlusion at the ostium of LAD, and the other was due to unsuccessful re-wiring through stent strut to LCX with a diameter less than $2.0 \mathrm{~mm}$.
Table 4 In-Hospital Outcomes

\begin{tabular}{lc}
\hline \hline & Patients $(n=113)$ \\
\hline Local complications & $2(1.8 \%)$ \\
Regional ischemic change $(\%)$ & 0 \\
Radial/femoral artery occlusion $(\%)$ & 0 \\
Local hematoma $(\%)$ & $2(1.8 \%)$ \\
Arteriovenous fistula $(\%)$ & 0 \\
Pseudoaneurysm $(\%)$ & 0 \\
c/w TIMI minor bleeding criteria $(\%)$ & 0 \\
c/w TIMI major bleeding criteria $(\%)$ & 0 \\
In-hospital CV event $(\%)$ & $10(8.8 \%)$ \\
Post-PCI MI $(\%)$ & $7(6.2 \%)$ \\
$Q$ wave $(\%)$ & 0.0 \\
Non- $Q$ wave $(\%)$ & $7(6.2 \%)$ \\
Repeat PCI $(\%)$ & 0 \\
CABG $(\%)$ & 0 \\
Acute/subacute thrombosis $(\%)$ & 0 \\
Stroke $(\%)$ & 0 \\
Pulmonary edema $(\%)$ & $1(0.9 \%)$ \\
VT/VF $(\%)$ & $1(0.9 \%)$ \\
Cardiac death $(\%)$ & $1(0.9 \%)$ \\
Total death $(\%)$ & $1(0.9 \%)$ \\
Mean duration of hospital stay (days) & $7.0 \pm 13.4$ \\
1-3 days (\%) & $59(52.2 \%)$ \\
4-7 days $(\%)$ & $28(24.8 \%)$ \\
8-14 days $(\%)$ & $19(16.8 \%)$ \\
$\geq 15$ days $(\%)$ & $7(6.2 \%)$ \\
&
\end{tabular}

c/w, compatible with; $C V$, cardiovascular; $M I$, myocardial infarction; VT, ventricular tachycardia; $V F$, ventricular fibrillation. Other abbreviations see in Tables 1-3.

\section{Procedural Characteristics}

Table 3 demonstrates the procedural details regarding PCI for ULMCA stenoses. Including the duration of ad hoc PCI to other coronary lesions performed in 59 patients $(52.2 \%)$ during this procedure, the mean procedure time was $84.0 \pm 33.9$ min. Eighty-one patients $(71.7 \%)$ had received PCI for ULMCA stenoses via left transradial approach. Most transradial PCI $(99.2 \%)$ in the present study were accomplished using either $6 \mathrm{Fr}(85 \%)$ or $7 \mathrm{Fr}$ $(14.2 \%)$ guiding catheters. One exception was a patient who underwent directional coronary atherectomy (DCA) using an 8 Fr catheter after 2-dimensional ultrasound measurement of the size of radial artery before PCI. The most commonly used catheters were Kimny radial or Kimny miniradial catheters, which were routinely selected as the initial diagnostic catheter in our lab and also utilized for PCI in 70 patients $(61.9 \%)$ in the present study. No patients ever received preventive implantation of transvenous temporal pacemaker, and intra-aortic balloon pumps (IABP) were implanted in 5 patients $(4.4 \%)$ owing to hemodynamic instability before PCI. Intravascular ultrasound was introduced to evaluate the ULMCA lesion or to guide PCI in 58 patients $(51.3 \%)$, and lesion modification by either DCA, rotational atherectomy or cutting balloon angioplasty was performed in 8 patients (7.1\%). Forty-nine patients (43.4\%) received stent implantation covering the ostium of ULMCA, while stents were implanted across the distal bifurcation of ULMCA in 89 patients $(78.8 \%)$. Direct stenting without balloon pre-dilatation was performed in 18 patients $(15.9 \%)$. The penetration rate of drug-eluting stent (DES), introduced in 2003, was $67.3 \%$, and the average number of stents used was $1.3 \pm 0.5$. Implantation of 1 stent with or without final kissing balloon technique was performed on $70.8 \%$ in the present study patients. Cullote $(16.8 \%)$ and modified crush techniques $(8.0 \%)$ were the 
second and third common techniques used in our series. In addition, 6 Fr or 7 Fr guiding catheters were feasible for all the techniques used for bifurcation stenting in the present study. The mean maximal pressure of balloon inflation was $18.7 \pm 5.6 \mathrm{~atm}$, and 87 patients $(77.0 \%)$ had high pressure inflation at no less than 16 atm. Additional non-compliant balloons were utilized in 42 patients and final kissing balloon technique was performed in 71 patients $(62.8 \%)$. The overall procedural success rate was $85.9 \%$, which was equal to the angiographic success rate.

\section{In-Hospital Outcomes}

Table 4 details in-hospital outcomes. No arteriovenous fistula or pseudoaneurysm after transradial PCI for ULMCA stenoses was observed in the present study. Although some patients experienced transient bleeding during hemostasis using an elastic bandage, and local hematoma $>5 \mathrm{~cm}$ in diameter over the wrist was noted in 2 patients $(1.8 \%)$, no case met TIMI major or minor criteria for bleeding complications. In addition, no cases of regional ischemic change were noted after release of the elastic bandage. No stroke, acute or subacute thrombosis, repetitive PCI or CABG occurred following the procedure. Post-procedural MI was noted in 7 patients $(6.2 \%)$, all of which presented as non-Q wave MI on ECG, and pulmonary edema occurred in 1 patient $(0.9 \%)$ due to $\mathrm{LV}$ dysfunction. One patient $(0.9 \%)$ suffered sudden-onset ventricular arrhythmia and subsequent cardiac death. This patient was the only case of allcause mortality following PCI for ULMCA stenoses recorded in our investigation. The mean duration of hospitalization was $7.0 \pm 13.4$ days, and 59 patients $(52.2 \%)$ were hospitalized for 3 days or less.

\section{One-Year Clinical Outcomes}

Fig 2 shows the Kaplan-Meier estimates of MACE-free survival, target vessel revascularization, all-cause death and cardiac death at 1 year. The mean and median follow-up duration was $8.9 \pm 4.1$ months and 11 months, respectively. One-year TLR was $14.2 \%$ and comprised a large portion of MACEs. One-year survival and MACE-free survival were $94.7 \%$ and $81.4 \%$, respectively. The 1 -year cardiac death rate was $3.5 \%$.

\section{Discussion}

The present study confirmed the high procedural success rate and low complication rate of transradial PCI for ULMCA stenoses. Transradial coronary angiography and angioplasty for coronary lesions excluding ULMCA stenoses have been documented as a safe alternative to transradial approach in Western as well as Asian populations, in case where LV function is preserved 10,11 Because of the small vessel size of the radial artery in comparison to the femoral artery, the major concern about transradial PCI for ULMCA stenoses is the feasibility of using relatively small guiding catheters to treat large, complex bifurcation lesions at the distal ULMCA area, especially when considering the use of directional or rotational atherectomy for debulking and kissing balloon techniques to optimize final angiographic results.

In contrast to Western populations, the present study of a Chinese population included subjects who were shorter and lighter, and had relatively small radial artery vessel sizes ${ }^{10,19}$ In addition, compliance and the ability of the radial artery to distend are reduced in patients with risk

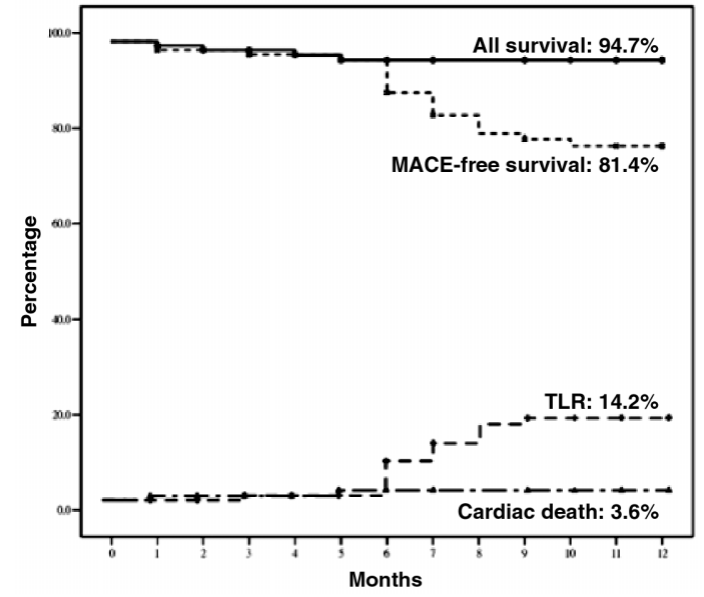

Fig 2. Kaplan-Meier estimates of 1-year survival, major adverse cardiac events (MACE)-free survival, target lesion revascularization (TLR) and cardiac death. Kaplan-Meier plots display the cumulative incidences of survival, MACE-free survival, TLR and cardiac death at 1 year after stenting.

factors such as atherosclerosis, and endothelial dysfunction of radial artery is believed to correspond with the severity of CAD 20,21 Nevertheless, a recent Korean study reported that the mean diameter of the radial artery was $2.60 \pm$ $0.41 \mathrm{~mm}$ and one Japanese study further revealed that the reduction of radial artery flow after transradial PCI was less likely if the ratio of radial artery diameter to sheath outer diameter was $\geq 1.022,23$ These findings suggest that the radial arteries of most patients can be cannulated with $6 \mathrm{Fr}$ artery sheaths, and 7 or $8 \mathrm{Fr}$ sheaths can be applied in selected patients to facilitate transradial PCI. Despite the selection bias from excluding most patients undergoing DCA, our investigation demonstrated that a 6 Fr guiding catheter could be applied in $85.0 \%$ of transradial PCI for ULMCA stenoses; however, because $43.4 \%$ of our patients had multiple CAD risk factors and multi-vessel CAD with prior history of transradial PCI to other coronary lesions, the failure rate of radial artery access was $6 \%$ in the present study and was higher than another study? 24

Another challenge of transradial PCI for UMLCA stenoses is radial spasm and the tortuosity of vascular beds, which might lead to difficulty in the advancement and torque of guiding catheters. To prevent potential spasms and future occlusion of radial artery, a the mixture of 5,000 units of unfractionated heparin, 200 $\mathrm{g}$ of nitroglycerin and $2.5 \mathrm{mg}$ of verapamil should be routinely administered into artery sheath immediately following cannulation of radial artery not only to ease discomfort, but also to facilitate further advancement of the 6 or 7 Fr guiding catheters along $0.035 \mathrm{~mm}$ regular Teflon-coated wire smoothly. In our catheterization lab, a more torturous vascular route may require a $0.035 \mathrm{~mm}$ hydrophilic Radifocus Guide Wire M (Terumo Corporation, Tokyo, Japan). Using a small size guiding catheter for transradial PCI also raises concerns about backup support, especially in patients with a large aortic root or high ULMCA ostium. However, due to use of the new guiding catheters with a curve designed specifically for the transradial approach, crossover to other puncture sites resulting from either vascular loop, vascular spasm or failed engagement of guiding catheters never occurred following successful cannulation of radial artery in the present study 25 These results demonstrate that the radial artery is a 
feasible access site for most patients undergoing PCI for ULMCA stenoses.

Small guiding catheters are less invasive and reduce complication as compared to large guiding catheters, but may not accommodate some PCI devices or techniques.26,27 With improved PCI instruments, the currently available largebore 6 Fr guiding catheter is suitable for a wider variety of stent deployment techniques, including modified crush, culottes and $\mathrm{T}$ stenting techniques, as well as the kissing balloon technique with one balloon of $3.5 \mathrm{~mm}$ and the other of $3.0 \mathrm{~mm}$ in diameter ${ }^{16}$ In addition, a large-bore 6 Fr guiding catheter can facilitate the utilization of intravascular ultrasound, cutting balloon and rotational atherectomy with burr size no more than $1.5 \mathrm{~mm}$. With 7 Fr guiding catheters, simultaneous kissing stent and standard crush techniques can be used for bifurcation stenting, and DCA with a specific instrument such as a FLEXI-CUT directional debulking system ${ }^{\mathrm{TM}}$ (Guidant Vascular Intervention Group, CA, USA) could be applied. The present study showed that, with various types of 6 Fr or 7 Fr guiding catheters, transradial PCIs for complex ULMCA lesions were usually successful, with a mean procedure time of less than $1.5 \mathrm{~h}$, more than half of our patients underwent ad hoc PCI to treat other coronary lesions during the procedure.

The potential drawback of transradial intervention is the injury to the accessed radial artery, which may be reused in subsequent transradial PCI or utilized as a vascular conduit for future $\mathrm{CABG}$. However, the vascular complications after transradial PCI for ULMCA stenoses were rare in the present study, which is consistent with previous studies of transradial $\mathrm{PCI} 28$ To minimize vascular complications, the radial artery sheath was removed immediately after the procedure, and hemostasis was accomplished by compressing folded gauze wrapped tightly by an elastic bandage for at least $60 \mathrm{~min}$. If no wound bleeding was noted, the tension of the elastic bandage would be relieved to allow adequate perfusion. In the present study, few of our patients experienced transient wound bleeding and subsequent forearm ecchymosis after hemostasis, and no patient had signs of ischemia in either forearm or hand after releasing the elastic bandage used for hemostasis. In one study comparing transfemoral to transradial left main PCI, 7 or 8 Fr catheters were used in $44.4 \%$ of the transradial group ${ }^{15}$ Major vascular complications only occurred in transfemoral group and mean fluoroscopy time, amount of contrast used, mean procedural time and procedure success were similar in both groups. That study concluded that transradial left main PCI was as fast and successful as the femoral approach and results in fewer vascular complications. These findings coincide with the results of the present study.

Although only 5 patients required IABP for pre-procedural hemodynamic instability, Briguori et al recommended that IABPs should be routinely implanted in high risk patients undergoing PCI for ULMCA stenoses to avoid hemodynamic changes during the procedure ${ }^{29}$ If the radial artery is selected as a route for PCI, bilateral femoral arteries can be reserved for implantation of IABP or even portable extracorporeal membrane oxygenator. The availability of femoral arteries for other invasive procedures during PCI for ULMCA is one of the advantages of the transradial approach.

Several studies have shown that the transradial approach resulted in a lower total procedure cost and a shorter hospitalization period than that of transfemoral approach ${ }^{30-32}$ Ziakas et al retrospectively compared 27 cases of transra- dial approach to 53 cases of transfemoral approach for both protected and unprotected left main PCIs 15 Although approximately half of the patients in their study had previously received $\mathrm{CABG}$, the transradial approach was found to result in fewer vascular complications and their study concluded that the transradial approach could be used by experienced operators as an effective approach in left main PCI for patients not in cardiogenic shock. Although the total cost was not calculated in the present study, the mean duration of required hospitalization was approximately 1 week, and more than half of patients were discharged within 2 days after transradial PCI for ULMCA. Most patients who underwent transradial PCI for ULMCA stenoses in the present study were able to walk immediately after the procedure and did not require extended hospitalization.

In-hospital outcomes showed excellent results comparable to other series of ULMCA stenting, mostly performed via the femoral artery3,7 According to the criteria proposed by the Academic Research Consortium, no patient had definite early thrombosis in the present study, but one cardiac death was considered as an event of probable early thrombosis. Elevated levels of CK, detection of $\mathrm{MB}$ fraction or ECG abnormalities were reported to occur in $5 \%$ to $30 \%$ of patients after PCI 33 No Q-wave MI was noted, and asymptomatic non-Q wave MI was the most common complication $(6.2 \%)$ in the present study. Nevertheless, the incidence was similar to that of other studies using PCI for ULMCA stenosis, ranging from 4 to $9 \%$ ? $, 34,35$

Although PCI for ULMCA stenosis is considered as a class III indication in established guidelines regarding whether $\mathrm{CABG}$ is eligible for patients, emerging studies of revasculization for ULMCA stenosis achieved by implantation of DES or bare metal stent revealed promising both short-term and long-term outcomes ${ }^{34-37}$ Additionally, 3 recent non-randomized observation studies demonstrated lower 1-year mortality rates in patients undergoing PCI for ULMCA stenosis as compared to those receiving CABG4,38,39 However, TLR was higher in PCI group than in CABG group although TLR was not always clinicaldriven in the PCI group. In the current study, 1-year TLR and all-cause deaths were $14.2 \%$ and $3.5 \%$, respectively, which are similar to the results in those studies comparing PCI to $\mathrm{CABG} 4,38,39$ Therefore, our findings support that transradial stenting for ULMCA stenoses has the same clinical benefits as previously shown in other studies and also provides a better quality of life without increasing mortality as compared to $\mathrm{CABG}$.

\section{Limitations of Study}

This retrospective, non-randomized trial did not compare the transradial approach to the transfemoral approach. However, due to the rarity of PCI for ULMCA stenosis and routine transradial approach for coronary angiography and PCI, the comparison was difficult because the accumulation of adequate case numbers of transfemoral PCI for ULMCA stenoses was not easy in our institute. Other limitations included a lack of records regarding changes in radial artery pulsation following the procedure and reuse of the same radial artery in subsequent procedures. Nevertheless, all patients showed no clinical sings of upper-limb ischemia.

\section{Conclusion}

The present study demonstrated a high success rate, a 
low complication rate and promising 1-year outcomes for transradial PCI for ULMCA stenoses. The transradial approach is a feasible and safe alternative to transfemoral approach, even in routines to perform PCI for ULMCA stenoses in most patients.

\section{References}

1. Tanihata S, Nishigaki K, Kawasaki M, Takemura G, Minatoguchi S, Fujiwara H. Outcomes of patients with stable low-risk coronary artery disease receiving medical- and PCI-preceding therapies in Japan: J-SAP study 1-1. Circ J 2006; 70: 365-369.

2. Fukunishi M, Nishigaki K, Okubo M, Kawasaki M, Takemura G, Minatoguchi S, et al. J-SAP study 1-2: Outcomes of patients with stable high-risk coronary artery disease receiving medical-preceding therapy in Japan. Circ J 2006; 70: 1012-1016.

3. Park SJ, Hong MK, Lee CW, Kim JJ, Song JK, Kang DH, et al. Elective stenting of unprotected left main coronary artery stenosis: Effect of debulking before stenting and intravascular ultrasound guidance. J Am Coll Cardiol 2001; 38: 1054-1060.

4. Chieffo A, Morici N, Maisano F, Bonizzoni E, Cosgrave J, Montorfano M, et al. Percutaneous treatment with drug-eluting stent implantation versus bypass surgery for unprotected left main stenosis: A single-center experience. Circulation 2006; 113: 2542-2547.

5. Furukawa Y, Tamura T, Toma M, Abe M, Saito N, Ehara N, et al. Sirolimus-eluting stent for in-stent restenosis of left main coronary artery in takayasu arteritis. Circ J 2005; 69: 752-755.

6. Valgimigli M, Malagutti P, Aoki J, Garcia-Garcia HM, Rodriguez Granillo GA, van Mieghem CA, et al. Sirolimus-eluting versus paclitaxel-eluting stent implantation for the percutaneous treatment of left main coronary artery disease: A combined RESEARCH and TSEARCH long-term analysis. J Am Coll Cardiol 2006; 47: $507-$ 514.

7. Chieffo A, Stankovic G, Bonizzoni E, Tsagalou E, Iakovou I, Montorfano M, et al. Early and mid-term results of drug-eluting stent implantation in unprotected left main. Circulation 2005; 111: 791 795 .

8. Laslett L. Normal left main coronary artery diameter can be predicted from diameters of its branch vessels. Clin Cardiol 1995; 18: $580-582$.

9. Black A, Cortina R, Bossi I, Choussat R, Fajadet J, Marco J. Unprotected left main coronary artery stenting: Correlates of midterm survival and impact of patient selection. J Am Coll Cardiol 2001; 37: $832-838$.

10. Kiemeneij F, Laarman GJ, de Melker E. Transradial artery coronary angioplasty. Am Heart J 1995; 129: 1 -7.

11. Wu CJ, Lo PH, Chang KC, Fu M, Lau KW, Hung JS. Transradial coronary angiography and angioplasty in Chinese patients. Cathet Cardiovasc Diagn 1997; 40: 159-163.

12. Rigattieri S, Ferraiuolo G, Palamara A, Loschiavo P. Transradial unprotected left main coronary artery stenting in an octogenarian with severe angina and Leriche syndrome. Am J Geriatr Cardiol 2006; 15: 235-238

13. Minden HH, Lehmann H, Meyhofer J, Butter C. Transradial unprotected left main coronary stenting supported by percutaneous Impella((R)) Recover LP 2.5 assist device. Clin Res Cardiol 2006; 95: $301-306$

14. Sunami K, Saito S, Tanaka S. Successful transradial coronary angioplasty and stenting using a self-expandable RADIUS stent to the anomalous left main coronary artery. J Invasive Cardiol 2003; 15: $46-48$.

15. Ziakas A, Klinke P, Mildenberger R, Fretz E, Williams MB, Della $\mathrm{SA}$, et al. Comparison of the radial and femoral approaches in left main PCI: A retrospective study. J Invasive Cardiol 2004; 16: 129 132.

16. Iakovou I, Ge L, Colombo A. Contemporary stent treatment of coronary bifurcations. J Am Coll Cardiol 2005; 46: 1446-14455.

17. Bovill EG, Terrin ML, Stump DC, Berke AD, Frederick M, Collen $\mathrm{D}$, et al. Hemorrhagic events during therapy with recombinant tissuetype plasminogen activator, heparin, and aspirin for acute myocardial infarction: Results of the Thrombolysis in Myocardial Infarction (TIMI), Phase II Trial. Ann Intern Med 1991; 115: 256-265.

18. Nashef SA, Roques F, Michel P, Gauducheau E, Lemeshow S, Salamon R. European system for cardiac operative risk evaluation (EuroSCORE). Eur J Cardiothorac Surg 1999; 16: 9-13.

19. Gwon HC, Doh JH, Choi JH, Lee SH, Hong KP, Park JE, et al. A 5Fr catheter approach reduces patient discomfort during transradial coronary intervention compared with a $6 \mathrm{Fr}$ approach: A prospective ran- domized study. J Interv Cardiol 2006; 19: 141-147.

20. Giannattasio C, Mancia G. Arterial distensibility in humans: Modulating mechanisms, alterations in diseases and effects of treatment. J Hypertens 2002; 20: 1889-1899.

21. Landmesser U, Merten R, Spiekermann S, Buttner K, Drexler H, Hornig B. Vascular extracellular superoxide dismutase activity in patients with coronary artery disease: Relation to endothelium-dependent vasodilation. Circulation 2000; 101: 2264-2270.

22. Yoo BS, Yoon J, Ko JY, Kim JY, Lee SH, Hwang SO, et al. Anatomical consideration of the radial artery for transradial coronary procedures: Arterial diameter, branching anomaly and vessel tortuosity. Int J Cardiol 2005; 101: 421-427.

23. Saito S, Ikei H, Hosokawa G, Tanaka S. Influence of the ratio between radial artery inner diameter and sheath outer diameter on radial artery flow after transradial coronary intervention. Catheter Cardiovasc Interv 1999; 46: 173-178.

24. Louvard Y, Krol M, Pezzano M, Sheers L, Piechaud JF, Marien C, et al. Feasibility of routine transradial coronary angiography: A single operator's experience. J Invasive Cardiol 1999; 11: 543-548.

25. Ikari Y, Nagaoka M, Kim JY, Morino Y, Tanabe T. The physics of guiding catheters for the left coronary artery in transfemoral and transradial interventions. J Invasive Cardiol 2005; 17: 636-641.

26. Resar JR, Prewitt KC, Wolff MR, Brinker JA. Coronary angioplasty through a new 6 French guiding catheter. Cathet Cardiovasc Diagn 1994; 32: 268-273.

27. Ueno K, Kotoo Y, Arai M, Matsubara T, Watanabe S, Ito H, et al. Coronary angioplasty using an over-the-wire balloon catheter through a new 6 French guiding catheter. Cathet Cardiovasc Diagn 1992; 26: $61-68$

28. Bazemore E, Mann JT III. Problems and complications of the transradial approach for coronary interventions: A review. J Invasive Cardiol 2005; 17: 156-159.

29. Briguori C, Airoldi F, Chieffo A, Montorfano M, Carlino M, Sangiorgi GM, et al. Elective versus provisional intraaortic balloon pumping in unprotected left main stenting. Am Heart J 2006; 152: $565-572$.

30. Louvard Y, Lefevre T, Allain A, Morice M. Coronary angiography through the radial or the femoral approach: The CARAFE study. Catheter Cardiovasc Interv 2001; 52: 181-187.

31. Cooper CJ, El-Shiekh RA, Cohen DJ, Blaesing L, Burket MW, Basu A, et al. Effect of transradial access on quality of life and cost of cardiac catheterization: A randomized comparison. Am Heart J 1999; 138: $430-436$

32. Kiemeneij F, Laarman GJ, Odekerken D, Slagboom T, van der Wieken R. A randomized comparison of percutaneous transluminal coronary angioplasty by the radial, brachial and femoral approaches: The access study. J Am Coll Cardiol 1997; 29: 1269-1275.

33. Califf RM, Abdelmeguid AE, Kuntz RE, Popma JJ, Davidson CJ, Cohen EA, et al. Myonecrosis after revascularization procedures. $J$ Am Coll Cardiol 1998; 31: 241-251.

34. Takagi T, Stankovic G, Finci L, Toutouzas K, Chieffo A, Spanos V, et al. Results and long-term predictors of adverse clinical events after elective percutaneous interventions on unprotected left main coronary artery. Circulation 2002; 106: 698-702.

35. Valgimigli M, van Mieghem CA, Ong AT, Aoki J, Granillo GA, McFadden EP, et al. Short- and long-term clinical outcome after drugeluting stent implantation for the percutaneous treatment of left main coronary artery disease: Insights from the Rapamycin-Eluting and Taxus Stent Evaluated At Rotterdam Cardiology Hospital registries (RESEARCH and T-SEARCH). Circulation 2005; 111: 1383-1389.

36. Smith SC Jr, Feldman TE, Hirshfeld JW Jr, Jacobs AK, Kern MJ, King SB III, et al. ACC/AHA/SCAI 2005 guideline update for percutaneous coronary intervention: A report of the American College of Cardiology/American Heart Association Task Force on Practice Guidelines (ACC/AHA/SCAI Writing Committee to Update the 2001 Guidelines for Percutaneous Coronary Intervention). J Am Coll Cardiol 2006; 47: e1-e121.

37. Lee BK, Hong MK, Lee CW, Choi BR, Kim MJ, Park KH, et al. Five-year outcomes after stenting of unprotected left main coronary artery stenosis in patients with normal left ventricular function. Int $J$ Cardiol 2006; 115: 208-213.

38. Lee MS, Kapoor N, Jamal F, Czer L, Aragon J, Forrester J, et al. Comparison of coronary artery bypass surgery with percutaneous coronary intervention with drug-eluting stents for unprotected left main coronary artery disease. J Am Coll Cardiol 2006; 47: 864-870.

39. Palmerini T, Marzocchi A, Marrozzini C, Ortolani P, Saia F, Savini $\mathrm{C}$, et al. Comparison between coronary angioplasty and coronary artery bypass surgery for the treatment of unprotected left main coronary artery stenosis (the Bologna Registry). Am J Cardiol 2006; 98: $54-59$. 